Dhaka Univ. J. Biol. Sci. 20(2): 131-138, 2011 (July)

\title{
IDENTIFICATION AND PATHOGENIC POTENTIALITY OF FUNGI ASSOCIATED WITH HOUTTUYNIA CORDATA THUNB.
}

\author{
RUMANA AZAD ${ }^{1}$ AND SHAMIM SHAMSI* \\ Department of Botany, University of Dhaka, Dhaka-1000, Bangladesh
}

Key words: Fungi, Association, Houttuynia cordata, Pathogenic potentiality

\begin{abstract}
A total of 17 species of fungi representing 11 genera were found to be associated with Houttuynia cordata Thunb. The isolated fungi were Aspergillus flavus Link, Aspergillus niger Van Tiegh., Cercospora houtttuyniicola Goh et Hsieh, Colletotrichum coffeanum Noack, Colletotrichum dematium (Pers. Ex Fr.) Grove, Colletotrichum gloeosporioides (Penz.) Sacc., Curvularia brachyspora Boedijn., Curvularia fallax Boedijn., Curvularia pallescens Boedijn., Fusarium sp., Nigrospora sacchari (Speg.) Mason., Penicillium sp., Pestalotiopsis spp., Syncephalastrum sp., Trichoderma viride Pers. Ex Fries. and a member of Zygomycetes. Cercospora houtttuyniicola is a new record for Bangladesh. All the isolated fungi were tested for pathogenicity.
\end{abstract}

\section{Introduction}

Houttuynia cordata Thunb. is the sole species in the genus Houttuynia of the family Saururaceae. It is a traditional medicinal herb and known as "Chameleon Plant". Its local name is "Aistya Gachh". This plant is native to Japan, Korea, Southern China and Southeast Asia. In Bangladesh it is found in Sylhet and Narail districts. ${ }^{(1)}$

The whole plant is antibacterial, antiinflammatory, antimicrobial, antiphlogistic, antiviral, depurative, diuretic, emmenagogue, febrifuge, hypoglycaemic, laxative and ophthalmic. Plant decoction is used internally in the treatment of many ailments including cancer, coughs, dysentery, enteritis and fever. Its use is said to strengthen the immune system. Externally, it is used in the treatment of snake bites and skin disorders. The leaf juice is antidote and astringent. A root extract is diuretic. The root is also said to be used in medicinal preparations for certain diseases of women. This plant is antitumorous and is a special medicine for lung cancer. ${ }^{(2-3)}$

A lot of research has been done on phytochemical, pharmacological and biochemical aspects of $H$. cordata. But research about its fungal disease is inadequate. So far Cercospora houttuyniicola has been reported on this plant from Taiwan. ${ }^{(4-5)}$

Two types of symptoms were found during the present investigation. These are anthracnose and leaf spots of which the former is the major one. The present studies were undertaken (i) to find out the association of the fungi with the healthy and infected plants and (ii) to detect the pathogenic potentiality of the associated fungi.

\footnotetext{
*Corresponding author: <Prof.shamsi@gmail.com>. ${ }^{1}$ A part of MS thesis of the first author (RA).
} 


\section{Materials and Methods}

Samples from healthy and infected leaves of Houttuynia cordata Thunb. were collected from the Botanical Garden, Curzon Hall campus, Dhaka University during November, 2008 to August, 2009. All the collected samples showed a number of associated fungi. Fourteen samples were examined.

The fungi were isolated from samples following the "Tissue Planting" method and "Blotter" method.(4)

In case of tissue planting method, 50 inocula each measuring 2 square mm were cut with a sterilized scalpel from a particular specimen and kept in a sterile Petri plate. The inocula were washed in sterile water and then surface sterilized by dipping in $10 \%$ Clorox for 3 - $5 \mathrm{~min}$. Then the inocula were transferred to a sterile Petri plate containing sterile blotting paper to remove the surface water. Then three inocula were placed in each plate containing sterilized Potato Dextrose Agar (PDA) medium and incubated for $5-7$ days at $25 \pm 2^{\circ} \mathrm{C}$.

In "Blotter" method, moist chambers were made by placing two layers of filter paper on the bottom of the Petri plates, moistened with sterilized water, covered with upper lids and were sterilized (autoclaved at $15 \mathrm{lbs}$ pressure and $120^{\circ} \mathrm{C}$ ). Squire $2 \mathrm{~mm}$ sized inocula were prepared from the leaf samples, surface sterilized with 10\% chlorox for 3 - 5 min. A total number of 50 inocula were transferred in ten Petri plates and incubated for $5-7$ days at $25-28^{\circ} \mathrm{C}$. The fungi growing out of the inocula were transferred to separate plates and slants for further studies and storage. Percentage association of the fungi was also recorded.

For microscopic observations fungal structures like mycelia, spore bearing structures and spore were scrapped off from the surface with a scalpel or blade or picked up with a needle and was mounted in lacto phenol over a clean slide for microscopic observation. In case of hyaline structures, a little amount of aniline blue was added to the mounted fluid.

Identification of isolates were determined by following the standard literatures.(7-9) All the specimens were preserved in the Herbarium, Mycology and Plant Pathology section, Department of Botany, University of Dhaka, Bangladesh.

The pathogenicity of all the isolated fungi were tested on detached leaf technique (modified).(10) Moist chamber was prepared by placing small cotton bar at the corner of Petri plate and autoclaved. Six treatments with three replications for each fungus was used as follows: control for unpricked and pricked leaves; dorsally inoculated unpricked and pricked leaves; and ventrally inoculated unpricked and pricked leaves.

All the test fungi were also inoculated on stem. The pricked and unpricked portion of stems were inoculated with $2 \mathrm{~mm}$ square mycelial block. Here four treatments with 
two replications for each fungus were used as follows: control for unpricked and pricked stems; and unpricked and pricked inoculated stems.

\section{Results and Discussion}

A total of 17 species of fungi representing 11 genera were found to be associated with Houttuynia cordata. Fungi were isolated from healthy and infected leaves (Fig. 1AC).
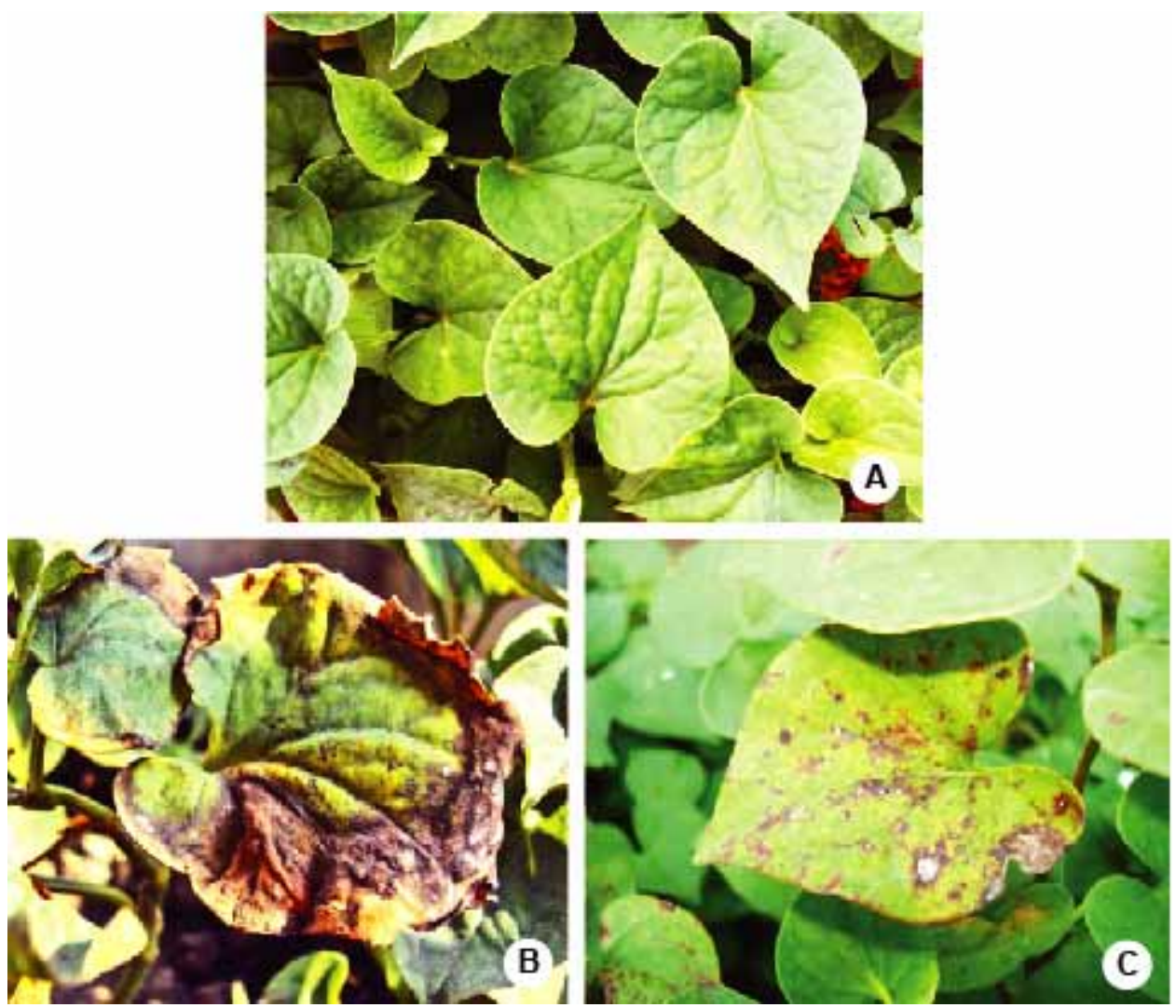

Fig. 1. A. Healthy plants of Houttuynia cordata, B. Anthracnose symptom and C. Leaf spot symptom.

Ten fungal species were isolated from healthy leaves of Houttuynia cordata of which the percentage of association of Pestalotiopsis sp.1 was highest (11.43).

In case of anthracnose symptom of the plant, 13 fungal species were isolated. Frequency of association of Colletotrichum gloeosporioides was highest (32.59\%; Table 1). 
Table 1. Frequency (\%) of association of fungi with leaves of Houttuynia cordata.

\begin{tabular}{lcc}
\hline Name of isolates & Healthy leaves & Diseased leaves (anthracnose) \\
\hline Aspergillus flavus & 0.95 & 3.33 \\
Aspergillus niger & 0.48 & 4.29 \\
Colletotrichum coffeanum & 7.62 & 7.62 \\
Colletotrichum dematium & - & 5.71 \\
Colletotrichum gloeosporioides & 8.10 & 32.59 \\
Curvularia brachyspora & 10.48 & 3.81 \\
Curvularia fallax & - & 3.33 \\
Curvularia pallescens & 4.76 & 2.86 \\
Fusarium sp. & - & 1.90 \\
Nigrospora sacchari & 1.90 & - \\
Penicillium sp. & 0.48 & - \\
Pestalotiopsis sp. 1 & 11.43 & 3.33 \\
Pestalotiopsis sp. 2 & 10.48 & 12.86 \\
Syncephalastrum sp. & - & 1.90 \\
Trichoderma viride & - & 1.90 \\
\hline
\end{tabular}

- = Not isolated.

Cercospora houttuyniicola was frequently associated with leaf spot symptom but did not isolated on culture plates. From leaf spot symptoms four fungal species were isolated. Frequency of Colletotrichum gloeosporioides was highest (40.0\%; Table 2).

Table 2. Frequency (\%) of association of fungi with infected leaves (spot) of Houttuynia cordata.

\begin{tabular}{lc}
\hline Name of fungi & Diseased leaves (leaf spot) \\
\hline Cercospora houttuyniicola & 13.34 \\
Colletotrichum gloeosporioides & 40.0 \\
Fusarium sp. & 10.0 \\
One unidentified lower fungus & 3.34 \\
\hline
\end{tabular}

The present report is the first record of Cercospora houttuyniicola from Bangladesh.

\section{Taxonomic enumeration of the newly recorded taxon}

Cercospora houttuyniicola Goh et Hsieh.

(Fig. 2A-D)

Leaf spots circular or irregularly suborbicular, $1-8 \mathrm{~mm}$ (mostly $2-4 \mathrm{~mm}$ ) in diameter, greyish brown in the center with a dark reddish brown margin, dead tissues may drop out leaving the leaf with holes. Fruiting amphigenous. Secondary mycelium absent. Stromata absent or a few brown cells. Conidiophores arise singly or 2 - 4 (rarely up to 10) in a fascicle, deep olivaceous brown to pale brown, paler towards the apex, 
irregular in width, curved, not branched, multiseptate, sometimes slightly constricted at the septa, $60-180 \times 4-7 \mu \mathrm{m}$. Conidial scars conspicuously thickened. Conidia acicular, hyaline, curved or undulate, indistinctly multiseptate, subacute at the apex, truncate at the base with a thickened hilum, $100-300 \times 3-4 \mu \mathrm{m}$. ${ }^{(5-6)}$
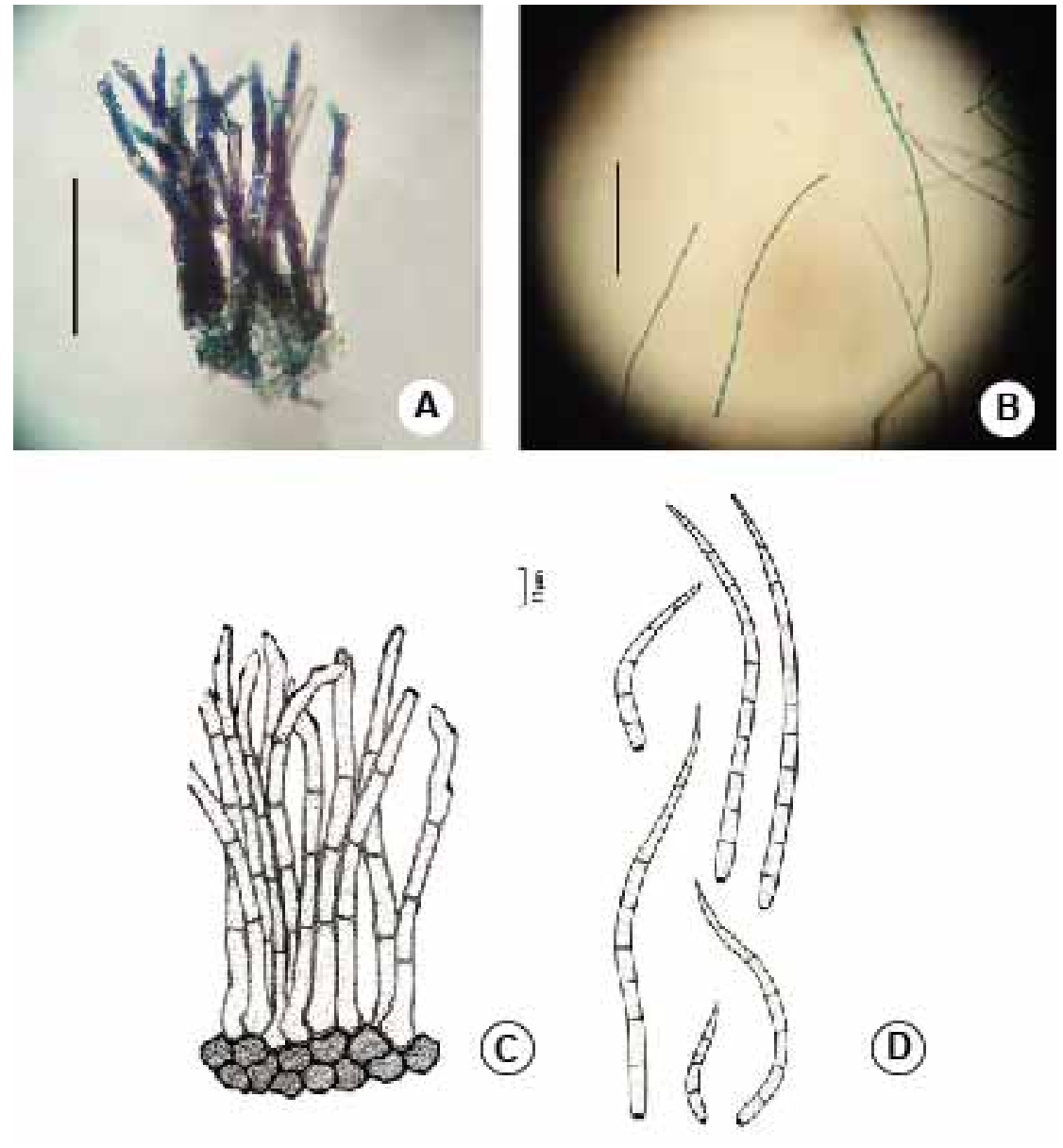

Fig. 2. A. Conidiophores, B. Conidia of Cercospora houttuyniicola. $($ Bar $=50 \mu \mathrm{m})$, C. Conidiophores and D. Conidia of Cercospora houttuyniicola.

All the isolated fungi were tested for pathogenic potentiality. Pathogenicity test following detached leaf inoculation technique revealed that Colletotrichum coffeanum, C. dematium and C. gloeosporioides produced symptoms on Houttuynia cordata (Fig. 3 and Table 3).

Colletotrichum coffeanum, C. dematium, and C. gloeosporioides were also capable of causing characteristic symptoms on inoculated stems (Fig. 4 and Table 4). 

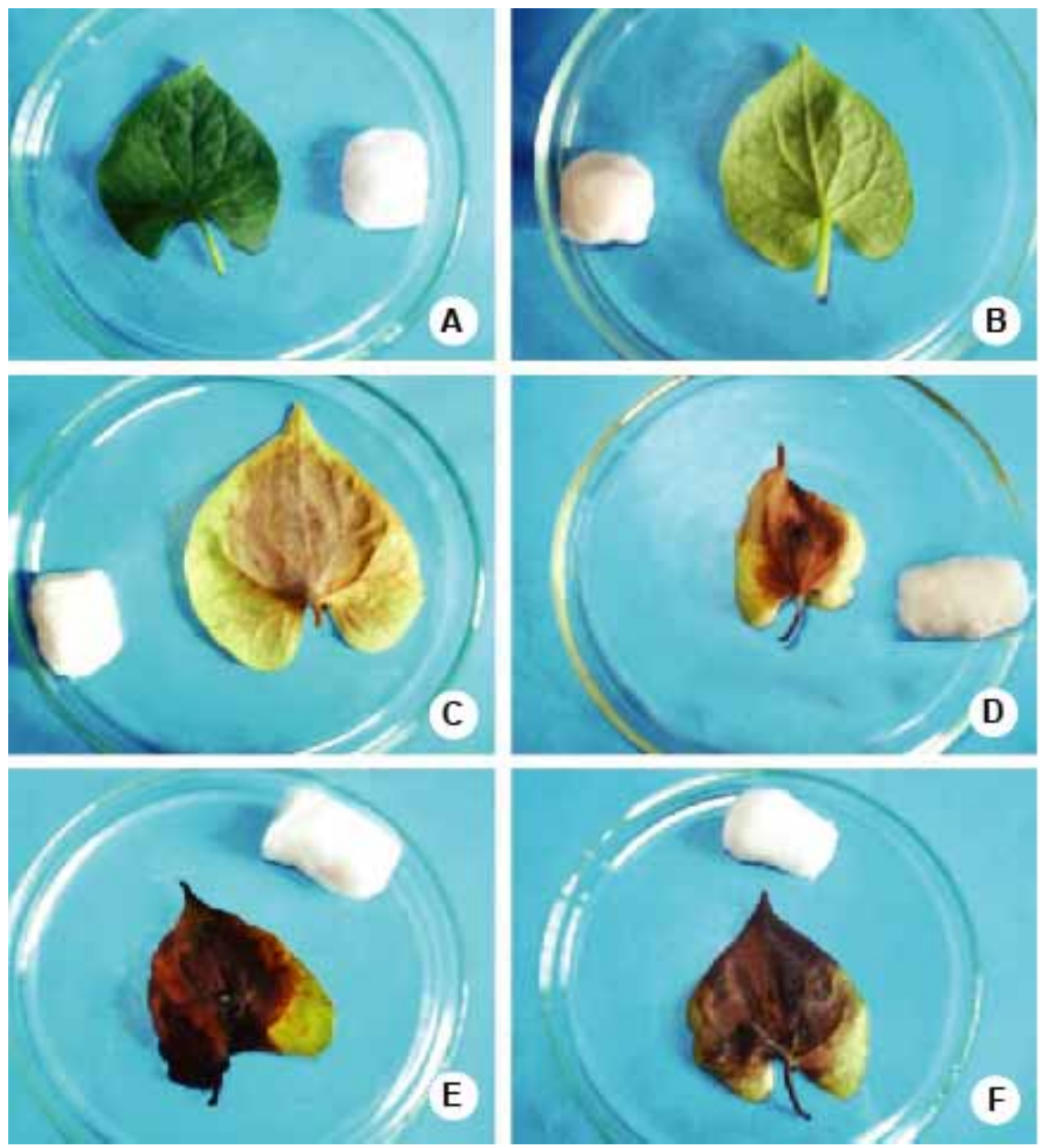

Fig. 3. A. Uninoculated dorsally pricked leaf of Houttuynia cordata, B. Uninoculated ventrally pricked leaf, C. Symptom produced by Colletotrichum coffeanum on ventrally inoculated leaf, D. Colletotrichum dematium on ventrally inoculated leaf, E. Colletotrichum gloeosporioides on dorsally inoculated leaf and F. Colletotrichum gloeosporioides on ventrally inoculated leaf.

Table 3. Response of the fungi to produce symptoms after inoculation on leaf.

\begin{tabular}{lccc}
\hline Inoculation & \multicolumn{3}{c}{ Response of the fungi } \\
\cline { 2 - 4 } type & Colletotrichum coffeanum & C. dematium & C. gloeosporioides \\
\hline T1 = Unpricked & - & - & - \\
T2 = Pricked & - & - & - \\
T3 $=$ Unpricked dorsally & - & - & - \\
T4 = Pricked dorsally & + & + & + \\
T5 $=$ Unpricked ventrally & - & - & - \\
T6 = Pricked ventrally & + & + & + \\
\hline
\end{tabular}

+ and - indicate positive and negative response, respectively. 

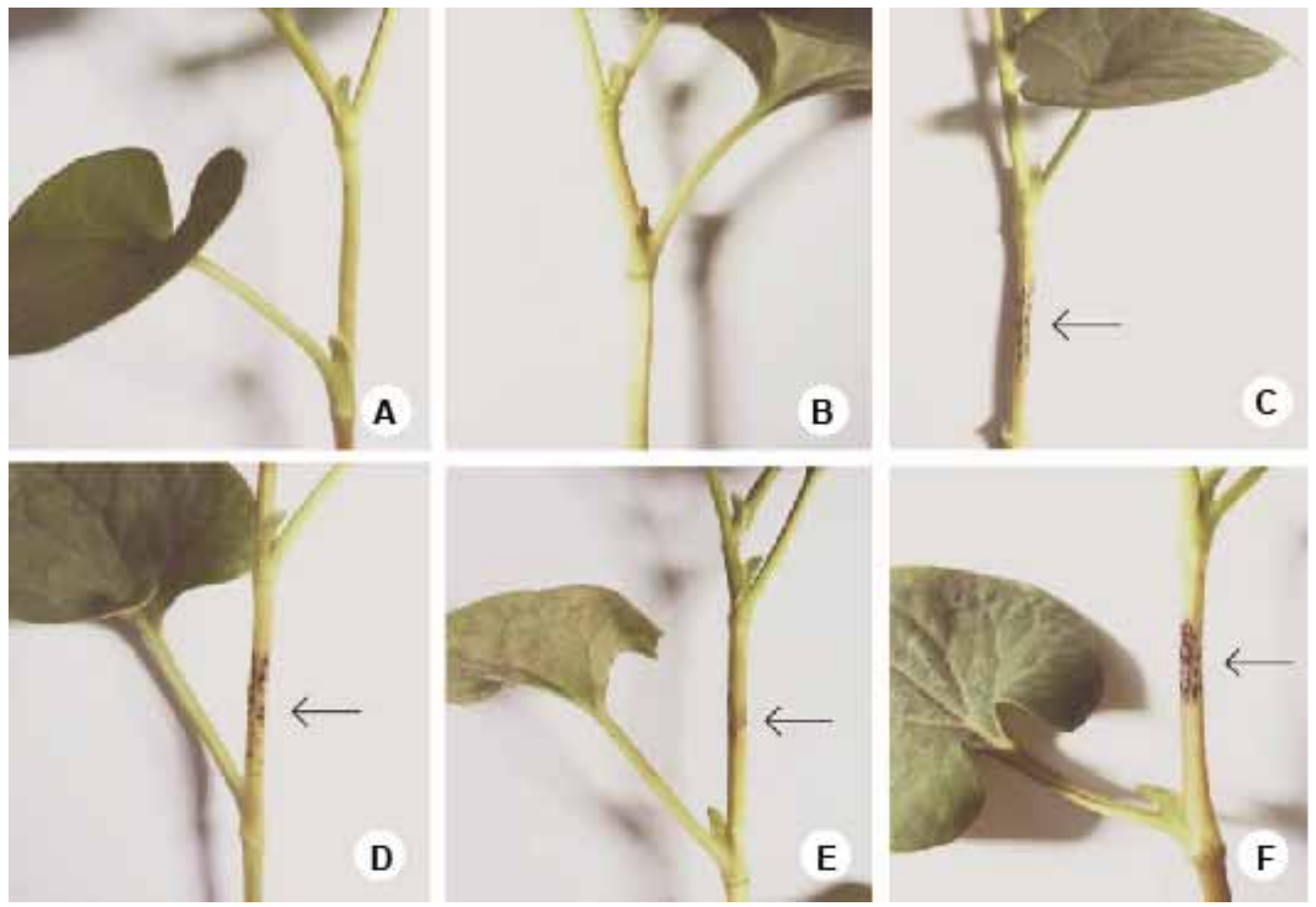

Fig. 4. A. Uninoculated unpricked stem of Houttuynia cordata, B. Uninoculated pricked stem, C. Symptom produced by Colletotrichum coffeanum on pricked stem, D. Colletotrichum dematium on pricked stem, E. Colletotrichum gloeosporioides on unpricked stem and F. Colletotrichum gloeosporioides on pricked stem.

Table 4. Response of the fungi to produce symptoms after inoculation on stem.

\begin{tabular}{lcccc}
\hline Inoculation & \multicolumn{3}{c}{ Response of the fungi } \\
\cline { 2 - 5 } type & Colletotrichum coffeanum & C. dematium & C. gloeosporioides \\
\hline T1 = Unpricked & - & - & - \\
T2 = Pricked & - & - & - \\
T3 = Unpricked inoculation & - & - & + \\
T4= Pricked inoculation & + & + & + \\
\hline
\end{tabular}

+ and - indicate positive and negative response, respectively.

Uninoculated unpricked and pricked leaves and stems (control) did not produce any symptom. It was revealed from the result that test fungi were capable of causing infection on pricked leaves and stems. In case of C. gloeosporioides only, unpricked stems inoculated by the fungus showed characteristic symptom.

The disease symptoms produced by Colletotrichum spp. were similar to those symptoms that were observed in nature. Each test fungus was reisolated from the artificially inoculated leaves and stems. 


\section{Acknowledgements}

Authors express their sincere thanks and gratitude to Professor Abul Hassan, Chairman, Department of Botany, University of Dhaka for providing all laboratory facilities for carrying out the present work. Special thanks are extended to Professor A. Z. M. Nowsher Ali Khan, Professor Abul Bashar and Professor Shahadat Morshed, Department of Botany, University of Dhaka, for their encouragement and cooperation during the course of the present work.

\section{References}

1. Ahmed ZU, MA Hassan, ZNT Begum, M Khondker, SMH Kabir, M Ahmed and ATA Ahmed. (eds.) 2009. Encyclopedia of Flora and Fauna of Bangladesh, Vol. 10. Angiosperms: Dicotyledons (Ranunculaceae-Zygophyllaceae). Asiatic Society of Bangladesh, Dhaka. pp. 227.

2. Dong KS, XQ Wang and YF Dong 1998. Xian Dai Lin Chuang Zhong Yao Xue [Contemporary Clinical Chinese Materia Medica]. Beijing: Zhong Guo Zhong Yi Yao Press.

3. Lin D, Y Sugitomo, Y Dong, H Terao and M Matsuo 2006. Natural herbicidal potential of Saururaceae (Houttuynia cordata Thunb.) dried powders on paddy weeds in transplanted rice. Crop Protection 25: 1126-1129.

4. $\mathrm{CAB}$ (Commonwealth Agricultural Bureau) 1968. Plant Pathologist's Pocket Book. The Commonwealth Mycological Institute. Kew. Surrey. England. pp. 267.

5. Goh TK and WH Hsieh 1988. New species of Cercospora and allied genera of Taiwan, Bot. Bull. Academia Sinica, pp. 117-132.

6. Rumana Azad 2010. Fungi associated with Houttuynia cordata Thunb., their identification and pathogenic potentiality. MS Thesis, Department of Botany, Univ. Dhaka. pp. vi+72.

7. Benoit MA and SB Mathur 1970. Identification of species Curvularia on rice seed. Proc. Inst. Seed Test. Ass. 35(1): 1-23.

8. Ellis MB 1971. Dematiaceous hyphomycetes. Commonwealth Mycological Institute, England. pp. 608.

9. Sutton BC 1980. The Coelomycetes, Fungi Imperfect with pycnidia acervuli and stroma, Commonwealth Mycological Institute. Kew, Surrey, England. pp. 525-537.

10. Shamsi S, N Naher and M Hossain 2008. Fungi associated with Smilax zeylanica L. and their pathogenic potentiality. Bangladesh J. Plant Pathol. 24(1\&2): 83-86. 